\title{
CONSTRUCTION SAFETY RISK ASSESSMENT WITH INTRODUCED CONTROL LEVELS
}

\author{
Murat GUNDUZ ${ }^{*}$, Heikki LAITINEN ${ }^{2}$ \\ ${ }^{1}$ Civil Engineering Department, Qatar University, PO Box: 2713 Doha, Qatar \\ ${ }^{2} 3$ T Results Ltd., Kumitehtaankatu 5, FIN-04260 Kerava, Finland
}

Received 27 October 2017; accepted 13 December 2017

\begin{abstract}
It is of great importance to facilitate the risk assessment process in construction projects because risk assessment is a requirement in most legislation and safety standards. A great majority of construction SMEs (Small and Medium Enterprises) are not familiar with risk assessment concepts and methods. In particular, SMEs are very likely to have difficulty finding the qualified personnel or time to carry out a proper risk assessment. The method introduced in this paper has some distinct features. The method introduces a new method of risk assessment, replacing the traditional definition of probabilities with control levels because they are easier to implement and yield more accurate risk scores. The method was practically applied on 22 construction SMEs. From the practical application, it was observed that the method was found to be user friendly and the SMEs found it easy to update their risk strategies during various construction stages in their projects. The proposed risk assessment method introduces a powerful and practical control level strategy which would develop a safer, healthier and more competitive workplace for construction SMEs.
\end{abstract}

Keywords: risk assessment, risk management, construction industry, control levels.

\section{Introduction}

Occupational safety and health has been and still is a topic of intense research and practical developments (Sousa et al. 2014). Safety management comprises several management processes, and risk assessment is a key process among them. It is of great importance to facilitate the risk assessment process in construction companies because occupational safety risk assessment is the core of safety practices (Pinto 2014) as well as a requirement in most safety related legislations. Corrective and preventive measures should be taken against particular risks at the workplace. Right measures can be determined only by identifying hazards and resulting risks correctly and thoroughly. However, one should not expect risk assessment to remove the hazards in a workplace in a short period of time. Rather, this can be achieved through a long-term persistent study; hence the underlying principle should be continuous improvement. It is also important for managers to promote training and communication about hazards and risks in the organization. This would increase risk awareness among personnel, and encourage active contribution for the purpose of removing the hazards. The risk assessment process should be supplemented by the continuous monitoring of the working conditions. This would monitor the root causes of occupational diseases and accidents in such areas as safety behaviour, mechanical hazards, ergonomics, order and tidiness.

This paper introduces an efficient and a user-friendly risk assessment methodology for construction companies of all sizes. In order to achieve the anticipated results of this risk assessment method, the utmost degree of management and worker participation is required. This risk assessment method has recently been introduced to the literature with unique characteristics which are discussed in the coming sections.

\section{Literature review}

A review of the previous safety assessment research was carried out to gather knowledge about various risk assessment techniques and proposed methodologies. There is a variety of literature that addresses safety risk assessment. The authors, however, report only the literature that they consider as the most relevant to the present study.

*Corresponding author. E-mail: mgunduz@qu.edu.qa 
The planning of safety is important. Hallowell (2011) presented a risk-based framework that can be used to evaluate the incremental return on the investment of a series of investments in highly effective injury prevention strategies. Aminbakhsh et al. (2013) also touch the same point. In their paper, a safety risk assessment framework that is based on the theory of cost of safety (COS) model and analytic hierarchy process (AHP) is presented. Choudhry (2017) investigated productivity and safety simultaneously on construction projects by conducting a survey. Lopez del Puerto et al. (2014) investigated the possible differences in safety culture and risk perception among Latino construction workers across residential, commercial, and heavy civil construction sectors. Gunduz and Laitinen (2017b) developed a 10-step safety management framework for construction SMEs.

Different models about risk assessment can be found in the literature. Tixier et al. (2017) introduced univariate and bivariate nonparametric stochastic safety risk generators based on kernel density estimators and copulas. Isaac and Edrei (2016) presented a statistical model that can support a more dynamic form of safety control, by utilizing real-time tracking data to control the exposure of construction workers to safety risks that accumulate and change over time. Malekitabar et al. (2016) provided five sets of safety risk drivers that can influence either the probability or the consequences of an accident, the application of which helps identify more than $40 \%$ of potential fatalities in construction projects. Karakhan and Gambatese (2017) conducted a credit-by-credit review of the leadership in energy and environmental design (LEED) rating system to evaluate the potential positive or negative impact of green design elements and construction practices associated with the implementation of LEED credits on the OHS of construction and maintenance workers. Choe and Leite (2017) compared safety risk of different construction trades in terms of common hazard types and sources of injuries and proposed safety risk quantification models by occupations, which can play a role as a safety reference for reliable safety risk assessment. Sousa et al. (2015) developed an Occupational Safety and Health Potential Risk Model (OSH-PRM) that enables an enhanced management of the resources available to improve safety and health conditions in the various activities and for different group of workers involved in the execution stage of a construction project. Raviv et al. (2107) reported on a multi-phase research that studied near misses related to crane work and their safety risk potential. Zhang et al. (2014) presented a probabilistic decision approach for safety risk analysis for metro construction in complex project environments. An expert confidence index that aims to ensure the reliability of collected data during expert investigation was proposed for the fuzzy probability estimation of basic events. Pinto (2014) presented the newly developed fuzzy QRAM model, which aims to support construction companies with their responsibilities to reduce occupational safety risks. Gunduz et al. (2017a) developed a fuzzy structural equation model for development of a safety performance index in construction sites. Same authors used the same model to develop a mobile application (Gunduz et al. 2018). Hallowell and Gambatese (2010) introduced and validated a risk-based safety and health analytical model that can be used to evaluate expected risk for specific worker activities. Their model strategically selects the most effective elements of a safety program for implementation when resources are limited, and quantifies the resulting risk once the identified safety elements have been implemented. Leu and Chang (2013) suggested the development of a safety risk-assessment model for steel building construction projects by establishing the Bayesian networks (BN) that are based on fault tree (FT) transformation. Esmaeili and Hallowell (2013) developed a decision support system using the Delphi method. This data-driven system produces predictive plots of a safety risk over time according to the temporal and spatial interactions among concurrent activities. Mitropoulos and Namboodiri (2011) presented the findings from the initial implementation of TDA (Task Demand Assessment) and demonstrated its feasibility and applicability on two different operations: a roofing activity and a concrete paving operation. The findings indicate that the method can be applied on activities of varying complexity and can account for several risks and task demand factors as required by the user. Fung et al. (2010) investigated the need for people involved in construction to take systematic and effective risk assessments for different trades. A Risk Assessment Model (RAM) was then developed for assessing the levels of risk for various project stages at various work trades. Dewlaney et al. (2012) and Fortunato et al. (2012) also made an analysis of safety assessment from the sustainability point of view. Gurcanli et al. (2015) aimed to give an approach for safety cost estimation for the early stages of construction bidding phase using risk assessment activities and construction project scheduling by focusing on construction activities.

This paper introduces a new, easy-to-use and userfriendly risk assessment methodology, which totally agrees with and adds up to the literature in the risk assessment area.

\section{Risk assessment as a part of the safety management}

The employer and safety experts have the responsibility to find out the possible safety and health hazards in the work environment. Then, if the hazards cannot be eliminated, they have to assess the possible safety and health effects and take the control measures that are necessary to avoid the possible accidents and diseases.

Construction industry is project industry. The whole production is derived from different projects, which may last from a few weeks to a few years. The duration of projects should also be taken into consideration in the organization of risk assessment. Risk assessment should be carried firstly during the project planning phase because it is possible to identify the potential safety problems and to take early actions in that stage. The experiences with the 
earlier project help to identify the possible problems in the coming projects. The construction production in building construction includes several different phases, such as the ground work phase, frame work phase and interior work phase. In each phase there are typical safety risks, thus the risk assessment should be carried out separately before each phase begins.

Technical and organizational improvements have priority when selecting the hazard control measures. It is also important for managers to promote training and communication about the hazards and risks in the organization. This would increase risk awareness among personnel and encourage safe working habits and active contribution to the purpose of removing hazards.

The continuous monitoring of both technical and human safety factors is important in order to keep the control measures updated at all times. The foremen have to take care of the safety as an indispensable part of their daily work. In some countries, the law requires a periodical safety inspection to be carried out at every construction site. A standardized monitoring tool has showed to be a valid indicator of the accident risk (Laitinen et al. 1999), as well as being effective in promoting continuous improvement (Laitinen, Päivärinta 2010).

Incident reporting includes both accidents and nearmisses. An investigation of these occurrences may reveal the necessity to update the risk assessment. OHS MS (Occupational Health and Safety Management System) auditing is used to keep all of the safety management processes updated in order to improve their efficiency.

\section{3TRA-CON (3T-RiskAssessment- Construction) methodology}

There are hundreds of risk assessment methods that are used for different purposes. The relevant literature was discussed in the earlier sections of this paper. Some methods are mainly used to analyse technical systems and processes; others are used to analyse human work activities and hazards in the working environment. There are also methods developed for particular industries. The 3TRACON method has been designed in such a way that it can be applied to SMEs as well as larger companies.

SMEs usually do not have reasonable expertise in all fields of OHS and all kinds of hazards. SME workplaces do not always understand the risks assessments carried out by their outside safety experts, and thus the control measures cannot be taken properly. Ready-made checklists help to find out the relevant hazards and to reduce the subjective effects. The special advantage of 3TRA-CON method for SMEs is its modular structure; it consists of ready-made check-list items divided in the basic modules, which cover all main risk factors. Each module includes a check list, and short description of each hazard as well as description of good workplace practices. Thus, the method itself includes basic OHS training package needed to identify the hazards and to assess the risks and the need for preventive and controlling actions. Modular structure made it also

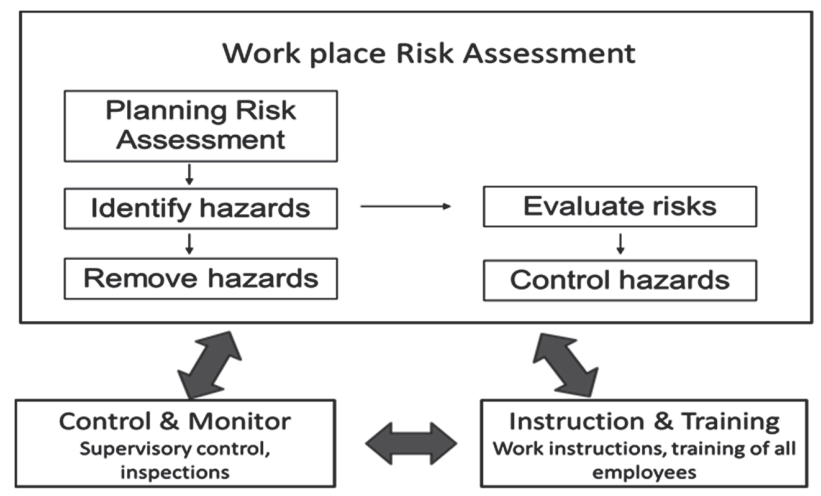

Figure 1. Risk assessment process and related training and monitoring processes

easy to modify the method for specific types of construction projects.

The 3TRA-CON method takes a general and inclusive approach to following the risk assessment steps given in Figure 1. It has several parts that cover a wide range of risk areas in a workplace. It also allows for the addition of new items and modules. This feature considerably reduces the burden of searching for risks from scratch, and the odds of leaving out an important hazard by mistake. Also, it introduces a new method of risk assessment by replacing the traditional definition of probabilities with control levels, which provides an easier perspective for implementation. The following sections will elaborate on the steps that should be followed in the 3TRA-CON method.

\section{Identifying hazards}

The OHS (Occupational Health and Safety) legislation and standards are based on scientific studies and long experiences with different hazards and stress factors at work. The majority of accidents and negative health issues in the workplace can be avoided when the OHS standards are followed. Thus, the main task concerning workplace risk assessment is to identify the hazards, and ensure compliance with the appropriate standard.

Risk assessment should cover all types of hazards in a workplace. Some hazards such as missing fall protection, missing machine safety guard, bad order of floor, and loud noise are obvious. Some hazards are more hidden. A hazard may hide itself behind rare and exceptional situations or work tasks. Other types of hidden hazards include those that cannot be detected by human senses, like fine dust, fumes, and radiation.

To identify and evaluate all remarkable hazards, it is necessary to involve different types of people in the risk assessment process. Consulting external experts is recommended if the workplace does not have sufficient expertise. For instance, hygienic measurements may be needed. Occupational health experts can especially help with healthrelated issues. It is also important to consult the personnel of the workplace. Engineers, supervisors, and workers or their representatives are experts of the processes and work tasks and thus know certain risks better than some outside 
experts. They also have the key role in developing and implementing the necessary preventive actions.

The 3TRA-CON includes a risk assessment checklist, and a short description of each hazard as well as a description of main legal requirements or good workplace practices. Thus, the method itself includes the basic OHS training package needed to identify the hazards and to assess the risks and need for preventive and controlling actions.

After gathering and reviewing background information, field tours should be carried out by internal or external safety experts; and processes should be observed to identify any potential hazards. In order to achieve this, every checklist item in each module should be addressed separately. While going over each item, the experts should observe the workplace and interview the engineers, supervisors, and, if necessary, workers too. The tasks that are occasionally or periodically performed, such as tunnel formwork, installation, transportation, job interruptions, and visits of outside visitors should be discussed. Notes should be taken on the 3TRA-CON forms about the observed hazards and present control measures. Some hazards can be easy to eliminate, so the required action can be decided on and noted during the tour. More difficult ones should, however, be delayed for risk evaluation and control.

Performing the actual risk assessment can take several days depending on the size of the company or construction site. A safety expert or staff member responsible for the OHS should perform the assessment. The occupational physician, if there is any, a management representative and a workers' representative should participate in the assessment process.

The basic items in the 3TRA-CON checklist can be listed as: 1) Walkways, access routes, stairs and ladders; 2) Scaffolding, temporary platforms and work stands; 3) Protection against falling and collapsing; 4) Electricity and lighting; 5) Order and tidiness; 6) Machinery and equipment; 7) Fire safety; 8) Physical hazards; 9) Chemical hazards; 10) Musculoskeletal strain factors; 11) Psychosocial stress factors; 12) First aid and emergency preparedness; 13) Welfare facilities; 14) Other hazards.

These items are essential for occupational safety and health in the construction sector. All of them are necessary to prevent accidents. Physical strain factors along with musculoskeletal strain factors are the two major problems for the type of construction in which the work is mainly done manually. Chemical and biological factors are inherent in the construction industry where dust and other air pollutants are prevalent in different production processes, like welding sandblasting, and painting. Besides, psychosocial strain factors are becoming more and more important especially for white collar employees.

\section{Evaluating risks and controlling hazards}

After the identification of hazards is completed, the hazards should be either removed or evaluated. There may be some easy and quick fixes that will eliminate a hazard all together. This is referred as the "remove hazards" step in Figure 1. These measures should be determined and proposed for the approval of the management. When implemented correctly, the measures will leave no risks at all, i.e. the accidents or diseases associated with the hazard before the implementation will be impossible to take place.

Some hazards are not easy to remove though; then an evaluation process will be necessary to assign relative scores to various risks. This information will be extremely valuable in determining the priorities in risk management. When appropriate risk scores are assigned, it will be easier to produce answers to the questions of which hazard or hazards should be dealt with first, what control measures should be implemented, and how much budget should be allocated to each hazard. This also enables the management to make short-term as well as long-term planning.

The risk evaluation process should be performed collectively in a meeting; a brainstorming session involving the manager or management representative, safety experts, occupational physicians, and related engineers and supervisors is advised. Here, the team should go over the module item by item and produce risk scores considering the severity and likelihood of potential accidents and occupational diseases.

Comparing risks is a difficult task. The difficulty lies in the fact that any risk has two major components as severity and likelihood. Some accidents will be more likely but the consequences are less severe, and some will be less likely but the consequences are more severe. The $3 \mathrm{~T}$ risk matrix provides an effective solution for this.

Categorical separation for the severity of an injury and illness is almost a straightforward task. It is only a matter of deciding on the number of categories (severity levels) and drawing the boundaries between them. The 3TRA-CON method has a particular separation approach that will be exemplified in the following sections.

Another aspect is the likelihood of injury or illness. The probability of future incidents is difficult to estimate. There are several reasons for this: first, there may be very limited or no record of a particular type of accident or illness in a workplace, which renders the estimation task very unreliable or even impossible. Second, the production safety level may change significantly on a daily or weekly basis. For example, untidiness of a worker in a certain week can increase the likelihood of an accident in that week. The wrong estimation of low likelihood in case of a potentially severe injury or illness is a common reason, or excuse, for not taking the necessary prevention actions.

In the 3TRA-CON, the likelihood estimation has been transformed into assessing how well the present controls of each hazard comply with the laws, standards and good practice. This can be done because most of the common hazards are already assessed when setting the OHS regulations and standards. When the present means of control meet the requirements, the likelihood of injury or illness should be low, and there may not be any need for improvements. What is unique in this method is that it is rather simple and concerning the assessment of the magnitude of a risk, it is using the level of control measures 
Table 1. The new risk assessment matrix

\begin{tabular}{|l|c|c|c|}
\hline \multirow{2}{*}{$\begin{array}{l}\text { Current level of prevention } \\
\text { and control }\end{array}$} & \multicolumn{3}{|c|}{ Potential severity of injuries \& diseases } \\
\cline { 2 - 4 } & 1. Slight & 2. Serious & 3. Major \\
\hline $\begin{array}{c}\text { 1. Control is sufficient } \mathbf{1}^{\mathrm{l} /} / \\
\text { no problems appeared }\end{array}$ & 1 & 1 & 2 \\
\hline $\begin{array}{c}\text { 2. Some need for improvement/ } \\
\text { problems have appeared }\end{array}$ & 2 & 3 & 4 \\
\hline $\begin{array}{c}\text { 3. Considerable need for } \\
\text { improvement/ Problems } \\
\text { exist often }\end{array}$ & 3 & 4 & 5 \\
\hline
\end{tabular}

1) Preventions and control is sufficient, when:

a) machines, tools and structures comply with law and standards

b) work is designed and organised to be safe and healthy

c) employees are trained, and they actually use right (safe) working practices

Table 2. The explanations of risk scores

\begin{tabular}{|c|l|l|l|}
\hline \multirow{2}{*}{$\begin{array}{c}\text { Current level of } \\
\text { prevention and } \\
\text { control }\end{array}$} & \multicolumn{3}{|c|}{ Potential severity of injuries \& diseases } \\
\cline { 2 - 4 } & \multicolumn{1}{|c|}{ 1. Slight } & \multicolumn{1}{c|}{ 2. Serious } & \multicolumn{1}{c|}{ 3. Major } \\
\hline $\begin{array}{c}\text { 1. Control is sufficient / } \\
\text { no problems appeared }\end{array}$ & $\begin{array}{l}\text { 1: Risk is } \\
\text { Insignificant. }\end{array}$ & $\begin{array}{l}\text { 1: A slight risk. } \\
\text { Keep observing the } \\
\text { situation. }\end{array}$ & $\begin{array}{l}\text { 2: A small risk. } \\
\text { Secure that the } \\
\text { problem remains } \\
\text { under control. }\end{array}$ \\
\hline $\begin{array}{c}\text { 2. Some need for } \\
\text { improvement/problems } \\
\text { have appeared }\end{array}$ & $\begin{array}{l}\text { 2: A small risk. } \\
\text { Keep observing the } \\
\text { situa-tion, and carry } \\
\text { out the easy } \\
\text { measures. }\end{array}$ & $\begin{array}{l}\text { 3: A average risk. } \\
\text { Plan and carry out } \\
\text { suitable measures. }\end{array}$ & $\begin{array}{l}\text { 4: A large risk. } \\
\text { Plan and carry } \\
\text { out the measures } \\
\text { quickly. }\end{array}$ \\
\hline $\begin{array}{c}\text { 3. Considerable need for } \\
\text { improvement/problems } \\
\text { exist often }\end{array}$ & $\begin{array}{l}\text { 3: A average risk. } \\
\text { Plan and carry out } \\
\text { suitable measures. }\end{array}$ & $\begin{array}{l}\text { 4: A large risk. } \\
\text { Plan and carry out } \\
\text { the measures } \\
\text { quickly. }\end{array}$ & $\begin{array}{l}\text { 5: A major risk. } \\
\text { Plan and carry } \\
\text { out the measures } \\
\text { immediately. }\end{array}$ \\
\hline
\end{tabular}

instead of the probability of a risk which in most cases is just a hypothetical value but not real. The new way of assessing the risks has several advantages: 1) it is much easier to check the present control measures than to estimate future incidents; and 2) this kind of checking directly indicates which kind of improvements may be necessary to comply with the legal requirements and good practice.

\section{6. $3 \mathrm{~T}$ risk matrix}

The new risk matrix of the 3TRA-CON is shown in Table 1 . It consists of the traditional 3-score severity scale, and the new 3-score control scale.

Severity scale is as follows:

1. Slight severe:

- slight injuries or distress, disability max 3 days.

2. Serious severe

- prolonged injury or disease, like simple wounds, fractures;

- disability max 30 days.

3. Major severe:

- permanent injury/illness or death;

- amputation of finger, second/third -degree burns, skull fractures, cancer, asthma.
Control scale is as follows:

1. Preventions and controls are sufficient; no problems have appeared.

2. There is some need for improvement, problems have appeared.

3. There is considerable need for improvement, problems often exist.

For each risk identified in a module, a risk score should be assigned according to the above rules. The 3TRA-CON forms have a column for writing scores across each risk. For example, when the estimate of severity is 3 and the estimate of present control is 2 , then the risk score is 4 .

Table 2 gives guidance for planning the preventive actions. Rapid preventive actions are needed when the score is 4 or 5 . In some cases it may be necessary to interrupt the use of hazardous equipment until safety measures are fully implemented. When an extremely severe hazard exists, you have to monitor the situation in order to keep a high level of control. For instance, the hazard of falling always exists when working on a scaffold. Therefore, you have to monitor the condition of railings and platforms. 


\section{Summary of risk scoring}

After completing the assignment of risk scores, the team should do brainstorming for possible proposals regarding the measures to be taken for improvement. The proposals should also be written in the corresponding table on the relevant risk assessment forms. The team may also prefer to estimate a future risk score that will be achieved when the proposed improvement measure is implemented. This is expected to provide further insight.

There is also a summary page for risk scores that can be submitted for review and approval of the company management. Another summary page exists for the preventive actions that have already been accepted by the management. The management may disapprove or delay some of the proposed measures, or may even not agree with the assigned scores. It is the responsibility of the management to make the final decisions. A sample form for summary of actions is presented in Table 3.

It is worthwhile to emphasize as a final note that it is not a good idea to assign the whole risk assessment process to a team of safety experts, and to leave them alone with the site managers, engineers and workers. Past experiences showed that this approach would produce unnecessary bureaucracy, conflicts of interests, incomprehensive assessment results, and planned but unfulfilled measures.
Instead, as long as the management is involved in the process and makes known to all the interested parties of their full support to the related activities, the risk assessment team will cooperate with the safety experts, make effort to raise risk awareness and correctly implement preventive measures.

\section{Application of 3TRA-CON in real cases}

The paper is the outcome of a European Union project named ISGIP. The project was specifically designed for specific conditions in SMEs. The project focused on SMEs functioning in metal, mining and construction sectors with employees between 10 and 250 in numbers. The project strategy relied on choosing 16 SMEs as Centre of Best Practices (CoBPs). All of 16 SMEs did sign a Memorandum of Understanding (MoU) with the project, which summarizes their commitments and those of the project team. The project considered and discussed economic, technical and resource situations of the companies and tried to improve their safety level for two years practically. The number of construction SMEs in this project was 22 (4 of them were CoBPs). These 22 construction SMEs were visited at least twice during the project timeline of two years.

Table 3. Summary of actions

\begin{tabular}{|c|c|c|c|c|}
\hline Item & Risk score & Description of action & Responsible & Time ready \\
\hline \multirow[t]{2}{*}{1} & 4 & All handrails are to be checked out daily & Related Person & DATE \\
\hline & 5 & The roofing is to be built above the entrance & Related Person & DATE \\
\hline \multirow[t]{3}{*}{2} & 3 & $\begin{array}{l}\text { The platforms are to be controlled and made free from } \\
\text { obstacles each day after compilation of work }\end{array}$ & Related Person & DATE \\
\hline & 5 & $\begin{array}{l}\text { Before the scaffolding is ready to use and marked } \\
\text { inspected, do not allow work on it }\end{array}$ & Related Person & DATE \\
\hline & 4 & Proper ladders are to be mounted and checked daily. & Related Person & DATE \\
\hline 3 & 5 & Install side protection on elevator openings & Related Person & DATE \\
\hline \multirow[t]{2}{*}{4} & 4 & $\begin{array}{l}\text { The damaged cable on the second floor is to be removed } \\
\text { and replaced with a new one }\end{array}$ & Related Person & DATE \\
\hline & 2 & Night lighting system must be installed before work begins & Related Person & DATE \\
\hline \multirow[t]{2}{*}{5} & 3 & $\begin{array}{l}\text { In the store heavy materials on the high self must be stored } \\
\text { in the lower shelf and light materials must be put on the } \\
\text { top shelf }\end{array}$ & Related Person & DATE \\
\hline & 3 & Make use of waste containers & Related Person & DATE \\
\hline \multirow[t]{3}{*}{6} & 5 & The circular saw must not be used until a guard is installed & Related Person & DATE \\
\hline & 3 & $\begin{array}{l}\text { Iron bending machine: Foot control panel is to be protected } \\
\text { by a guard to prevent unintentional press }\end{array}$ & Related Person & DATE \\
\hline & 4 & Lifting equipment has to be checked and repaired & Related Person & DATE \\
\hline \multirow[t]{2}{*}{7} & 1 & Fire extinguisher must be checked every for proper use & Related Person & DATE \\
\hline & 2 & Smoking area must be defined and marked & Related Person & DATE \\
\hline 8 & 2 & $\begin{array}{l}\text { Hearing Protection is not used properly. This has to be } \\
\text { addressed in training programs }\end{array}$ & Related Person & DATE \\
\hline 9 & 3 & Suitable respirators must be supplied & Related Person & DATE \\
\hline
\end{tabular}


Company / site: Assessment made by: Work processes assessed:
ABC Construction Inc. OHS Expert Tunnel Formwork
Date: 28.11 .2017

IHIS IS AN EXAMPLE OF HOW TO COMPLETE THE FOR

\begin{tabular}{|c|c|c|c|c|c|c|c|}
\hline 1 & 2 & 3 & 4 & 5 & 6 & 7 & 8 \\
\hline \multicolumn{2}{|r|}{$\begin{array}{l}\text { Item to be assessed: } \\
\text { Walkways, access routes, stairs and ladders }\end{array}$} & $\begin{array}{l}\text { Possible problems in control or } \\
\text { improvements in control }\end{array}$ & 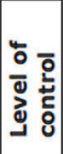 & 至 & 는 임 & $\begin{array}{l}\text { Responsible } \\
\text { person/ } \\
\text { when it } \\
\text { should be } \\
\text { done }\end{array}$ & $\begin{array}{l}\text { Ready } \\
\text { Date }\end{array}$ \\
\hline \multirow{8}{*}{1} & \multirow{8}{*}{\begin{tabular}{|l} 
Walkways, access routes, stairs and ladders \\
- Ladders in good condition, used only for \\
temporary access, or for short- \\
term light work with one hand \\
- Wide enough \\
- Free off obstacles, not slippery \\
- No openings or cracks, which may cause \\
falling \\
- Handrails and mid rails to prevent fall of \\
persons when falling distance is more \\
than 0,5 m. \\
- Proper roofing in entrance of the building \\
to stop falling objects
\end{tabular}} & $\begin{array}{l}\text { 1. Some mid rails are missing. All handrails are } \\
\text { to be checked out daily. }\end{array}$ & 2 & 3 & 4 & & \\
\hline & & $\begin{array}{l}\text { 2. The entrance of building needs roofing in } \\
\text { order to keep workers safe from falling } \\
\text { objects }\end{array}$ & 3 & 3 & 5 & & \\
\hline & & & & & & & \\
\hline & & & & & & & \\
\hline & & & & & & & \\
\hline & & & & & & & \\
\hline & & & & & & & \\
\hline & & & & & & & \\
\hline
\end{tabular}

Figure 2. Sample assessment for the risk assessment

Any type of risk could be assessed with this methodology. In order to provide an insight to the exercise, a real case study (without mentioning the company names and the safety expert) is introduced in Figure 2. As an example, only the assessment of "walkways, access routes, stairs and ladders" was introduced. However, this exercise could be repeated for any hazard specific to that construction project.

The risk assessment method fulfilled the following needs: 1) compatible with legal requirements, and the requirements of OHS MS standards; 2) comprehensive enough, including checklists and basic information about hazards; and 3) easy to learn and simple to use also by company line managers and employees. The method was experimented in the CoBPs in order to get experiences for further development. The following steps were taken during the study with CoBPs in construction sector: 1) company personnel was trained for effective use of 3TRA-CON method; 2) company processes were identified, including, non-routine as well as routine tasks, activities taking outside the company premises are also considered; 3 ) risk assessment of the construction site was conducted in a group consisting of project experts, company OHS representatives, workers representatives, OHS expert, occupational physician, where available. Hazard identification was conducted with the help of previous data including previous risk assessments and incidents. Identified hazards were assessed using the 3TRA-CON matrix. Suggestions were discussed for improvement; in some cases, the residual risk (after control actions) was also assessed. The 3TRA-CON method proved to be a good basis for development of the RA method for construction SMEs.

\section{Conclusions}

Occupational health and safety management is based on the assessment of workplace conditions for possible risks. Risk assessment can be done by using different risk assess- ment methods. This study developed the 3TRA-CON Risk Assessment method to be used in the construction sector.

The crucial task is to identify the hazards and current control measures. Traditional methods include a hazard checklist for this purpose. The 3TRA-CON includes a hazard checklist too, but it also includes short descriptions of adequate control measures for each hazard, which helps to reveal the shortcomings of control measures.

After hazard identification, the evaluation takes place. Traditional methods include the assessment of the likelihood of an injury or illness, which is a difficult task. In the 3TRA-CON method, this has been replaced by assessing the adequacy of existing control measures. The current situation is being compared with the legal requirements.

The safety expert has the responsibility to carry out the risk assessment. They often use complicated methods, and the results are difficult to communicate to managers and workers. The resulting risk assessment is often "paperwork" with only minor influence on safety. This paper introduces an efficient and user-friendly risk assessment methodology for construction companies of all sizes. It can be used by safety experts and/or site managers as well as workers' safety representatives.

Potential research topics for improving safety risk assessment of construction projects would be the development of a mobile device application of the currently proposed methodology. Moreover, the methodology could be applied to compare risk assessment among different project types in construction industry.

\section{Acknowledgements}

The authors would like to thank the Central Finance and Contracts Unit (CFCU) for continuous support during all phases of the ISGIP project. The authors would also like to thank the experts of the Turkish Ministry of Labour and Social Security for their support and valuable 
contribution. The corresponding author was the long-term construction sector expert and a full-time faculty at Middle East Technical University during the project timeline. Special thanks go to the construction team members of the project and all other key and non-key experts of the project.

\section{References}

Aminbakhsh, S.; Gunduz, M.; Sonmez, R. 2013. Safety risk assessment using analytic hierarchy process (AHP) during planning and budgeting of construction projects, Journal of Safety Research 46: 99-105.

http://dx.doi.org/10.1016/j.jsr.2013.05.003

Choe, S.; Leite, F. 2017. Assessing safety risk among different construction trades: Quantitative approach, Journal of Construction Engineering and Management 143(5), 04016133. http://dx.doi.org/10.1061/(ASCE)CO.1943-7862.0001237

Choudhry, R. M. 2017. Achieving safety and productivity in construction projects, Journal of Civil Engineering and Management 23(2): 311-318.

http://dx.doi.org/10.3846/13923730.2015.1068842

Dewlaney, K. S.; Hallowell, M. R.; Fortunato III, B. R. 2012. Safety risk quantification for high performance sustainable building construction, Journal of Construction Engineering and Management 138(8): 964-971. http://dx.doi.org/10.1061/(ASCE)CO.1943-7862.0000504

Esmaeili, B.; Hallowell, M. 2013. Integration of safety risk data with highway construction schedules, Construction Management and Economics 31(6): 528-541. http://dx.doi.org/10.1080/01446193.2012.739288

Fortunato III, B. R.; Hallowell, M. R.; Behm, M.; Dewlaney, K. 2012. Identification of safety risks for high-performance sustainable construction projects, Journal of Construction Engineering and Management 138(4): 499-508.

http://dx.doi.org/10.1061/(ASCE)CO.1943-7862.0000446

Fung, I. W. H.; Tam, V. W. Y.; Lo, T. Y.; Lu, L. L. H. 2010. Developing a risk assessment model for construction safety, International Journal of Project Management 28(6): 593-600. http://dx.doi.org/10.1016/j.ijproman.2009.09.006

Gunduz M.; Laitinen, H. 2017b. A 10-step safety management framework for construction SMEs, International Journal of Occupational Safety and Ergonomics 23(3): 353-359.

http://dx.doi.org/10.1080/10803548.2016.1200258

Gunduz, M.; Birgonul T.; Ozdemir, M. 2018. Development of a safety performance index assessment tool by using a fuzzy structural equation model for construction aites, Automation in Construction 85: 124-134.

http://dx.doi.org/10.1016/j.autcon.2017.10.012

Gunduz, M.; Birgonul, T.; Ozdemir, M. 2017a. Fuzzy structural equation model to assess construction site safety performance, Journal of Construction Engineering and Management 143(4). http://dx.doi.org/10.1061/(ASCE)CO.1943-7862.0001259

Gurcanli, G. E.; Bilir, S.; Sevim, M. 2015. Activity based risk assessment and safety cost estimation for residential building construction projects, Safety Science 80: 1-12. http://dx.doi.org/10.1016/j.ssci.2015.07.002

Hallowell, M. R. 2011. Risk-based framework for safety investment in construction organizations, Journal of Construction Engineering and Management 137(8): 592-599. http://dx.doi.org/10.1061/(ASCE)CO.1943-7862.0000339
Hallowell, M.; Gambatese, J. 2010. Population and initial validation of a formal model for construction safety risk management, Journal of Construction Engineering and Management 136(9): 981-990. http://dx.doi.org/10.1061/(ASCE)CO.1943-7862.0000204

Isaac, S.; Edrei, T. 2016. A statistical model for dynamic safety risk control on construction sites, Automation in Construction 63: 66-78. http://dx.doi.org/10.1016/j.autcon.2015.12.006

Karakhan, A. A.; Gambatese, J. A. 2017. Identification, quantification, and classification of potential safety risk for sustainable construction in the United States, Journal of Construction Engineering and Management 143(7), 04017018. http://dx.doi.org/10.1061/(ASCE)CO.1943-7862.0001302

Laitinen, H.; Marjamäki, M., Päivärinta, K. 1999. The validity of the TR safety observation method on building construction, Accident Analysis and Prevention 31: 463-472.

http://dx.doi.org/10.1016/S0001-4575(98)00084-0

Laitinen, H.; Päivärinta, K. 2010. A new-generation safety contest in the construction industry - a long-term evaluation of a real-life intervention, Safety Science 48: 680-686.

http://dx.doi.org/10.1016/j.ssci.2010.01.018

Leu, S.-S.; Chang, C.-M. 2013. Bayesian-network-based safety risk assessment for steel construction projects, Accident Analysis and Prevention 54: 122-123.

http://dx.doi.org/10.1016/j.aap.2013.02.019

Lopez del Puerto, C.; Clevenger, C.; Boremann, K.; Gilkey, D. 2014. Exploratory study to identify perceptions of safety and risk among residential Latino construction workers as distinct from commercial and heavy civil construction workers, Journal of Construction Engineering and Management 140(2). http://dx.doi.org/10.1061/(ASCE)CO.1943-7862.0000794

Malekitabar, H.; Ardeshir, A.; Sebt, M. H.; Stouffs, R. 2016. Construction safety risk drivers: A BIM approach, Safety Science 82: 445-455. http://dx.doi.org/10.1016/j.ssci.2015.11.002

Mitropoulos, P.; Namboodiri, M. 2011. New method for measuring the safety risk of construction activities: Task demand assessment, Journal of Construction Engineering and Management 137(1): 30-38.

http://dx.doi.org/10.1061/(ASCE)CO.1943-7862.0000246

Pinto, A. 2014. QRAM a qualitative occupational safety risk assessment model for the construction industry that incorporate uncertainties by the use of fuzzy sets, Safety Science 63: 57-76. http://dx.doi.org/10.1016/j.ssci.2013.10.019

Raviv, G.; Shapira, A.; Fishbain, B. 2017. AHP-based analysis of the risk potential of safety incidents: Case study of cranes in the construction industry, Safety Science 91: 298-309. http://dx.doi.org/10.1016/j.ssci.2016.08.027

Sousa, V.; Almeida, N. M.; Dias, L. A. 2014. Risk-based management of occupational safety and health in the construction industry - Part 1: Background knowledge, Safety Science 66: 75-86. http://dx.doi.org/10.1016/j.ssci.2014.02.008

Sousa, V.; Almeida, N. M.; Dias, L. A. 2015. Risk-based management of occupational safety and health in the construction industry - Part 2: Quantitative model, Safety Science 74: 184-194. http://dx.doi.org/10.1016/j.ssci.2015.01.003

Tixier, A. J.-P.; Hallowell, M. R.; Rajagopalan, B. 2017. Construction safety risk modeling and simulation, Risk Analysis 37(10): 1917-1935. http://dx.doi.org/10.1111/risa.12772

Zhang, L.; Skibniewski, M. J.; Wu, X.; Chen, Y.; Deng, Q. 2014. A probabilistic approach for safety risk analysis in metro construction, Safety Science 63: 8-17. http://dx.doi.org/10.1016/j.ssci.2013.10.016 